\title{
Validating report of first episode of wheezing with pediatrician-detected wheezing among children
}

\author{
DOI:10.1111/pai.12141
}

To the Editor,

Acute respiratory illness (ARI) is one of the commonest diseases among young children, and it is mainly associated with viral infections (1). This illness is an important source of morbidity, especially in the first year of life (2). Most respiratory viral infections in early childhood are limited to the upper respiratory tract, leading to common cold symptoms (3). Nonetheless, about one-third of infants with ARI develop lower respiratory tract symptoms such as tachypnea, wheezing, severe cough, breathlessness, and respiratory distress (3). Although all infants get viral respiratory infections, most of them do not wheeze. We aimed to estimate the frequency of the first episode of wheezing among children aged 6-23 months with ARI and to validate the first report of wheezing by the caregiver with detection of wheezing on physical examination by the pediatrician.

This prospective cross-sectional study was conducted between September 2009 and June 2011, at the Emergency Department of Federal University of Bahia hospital in Salvador, Brazil. As the central hypothesis was that report of wheezing by the caregiver was predictor of the first episode of wheezing among the studied patients, those aged under 6 months were excluded because of lesser frequency of wheezing in this age group.

Pediatricians from this setting provide primary care for short-course complaints. Children with fever, sneeze, running nose, nasal blockage, or cough for $\leq 7$-days were evaluated (inclusion criteria). Children transferred from other hospitals or reporting previous episode of wheezing were excluded (exclusion criteria). This study was approved by the institutional Ethics Research Committee, and parents/legal guardians signed the written informed consent before recruitment.

For the eligible children, a standardized questionnaire was filled out. Data on the current illness complaints, mother occupation, breastfeeding, and other children living in the same household were asked. Data on physical examination performed by the pediatrician were registered. The patients were examined just after the registration of the complaints during the medical consultation, before any intervention. Caregiverreported wheezing was defined as wheezing reported by the caregiver as one of the ongoing complaints during the current visit in the Emergency Department. Pediatrician-documented wheezing was defined as the detection of a whistling sound produced in the respiratory airways attributable to narrowed respiratory airways by the pediatrician using the stethoscope. Fever was defined as axillary temperature $>37.4^{\circ} \mathrm{C}$ (4), and tachypnea as respiratory rate $(\mathrm{RR}) \geq 50$ breaths/minute in children aged $6-11$ months and $R R \geq 40$ breaths/minute in children aged $\geq 12$ months (5).

Data analysis was performed with the STATA program (version 11.0). We estimated the prevalence of firstly reported and detected wheezing (and their respective 95\% confidence intervals $[\mathrm{CI}]$ ). Bivariate and multivariate analyses, using Poisson regression models, with robust variance, were performed to identify possible associations of disagreement between reported and detected wheezing with independent variables. Two criteria were used to select variables for the final model: first, $p$-value $\leq 0.05$ in the bivariate analysis and, second, a clear change ( $10 \%$ or more) in the estimates of the effects of the exposures produced by the other variables not selected in the first step of the analysis. The sensitivity, specificity, positive predictive value (PPV), and negative predictive value (NPV) of report of wheezing were calculated, taking detection of wheezing on physical examination as the gold standard.

Among 451 children who fulfilled the inclusion criteria, 164 $(36.4 \%)$ reported previous episode of wheezing, $6(1.3 \%)$ came from other hospital, and $3(0.7 \%)$ reported both. Thus, we recruited $281(62.3 \%)$ eligible children. There were $49.8 \%$ males, the median age was 10 months (mean $11.3 \pm 4.4$ ), 189 $(67.3 \%)$ were $<1$ year old. Among the mothers, $55.3 \%$ worked or studied out of home.

Most children (94\%) were breastfed, and 44.7\% were still being breastfed at the time of recruitment. First episode of wheezing was reported by $124(44.1 \%$; 95\% CI: 38.3-50.2\%) and $82(43.4 \%$; 95\% CI: 36.3-50.8\%) among those $<1$-yearolds and $42(45.7 \%$; 95\% CI: $35.3-56.3 \%)$ among those aged $\geq 1$ year.

On physical examination, red eyes $(24.6 \%)$, tachypnea $(28.7 \%)$, fever $(37.1 \%)$, and cough $(75.1 \%)$ were observed, and $75.8 \%$ of those presenting cough had wet cough. Most children had running nose $(70.1 \%)$ and nasal blockage $(65.1 \%)$. On auscultation, rhonchi $(37.4 \%)$ and crackles $(7.8 \%)$ were identified in addition to wheezing $(16.4 \%$; $95 \%$ CI: $12.3-$ $21.3 \%)$. Wheezing was detected in $34(18.0 \%$; $95 \%$ CI: $12.9-$ $24.4 \%)$ children aged $<1$ year and in $12(13.0 \%$; $95 \% \mathrm{CI}$ : $7.2-22.1 \%)$ aged $\geq 1$ year. Wheezing was reported in $30(65 \%)$ of 46 true wheezers, and wheezing was detected in $30(24 \%)$ of 124 who reported wheezing. No child presented other concomitant illness. Rhinitis was reported by 22 (8\%) of 275 responders and atopic dermatitis by $2(0.7 \%)$ of 281 responders. There was no association between those with rhinitis or atopic dermatitis with report of wheezing, detection of wheezing, or concordance between report and detection of wheezing (data not shown).

Sensitivity $(65 \% ; 95 \%$ CI: 50-79\%), Specificity $(60 \% ; 95 \%$ CI: $53-66 \%)$, PPV (24\%; 95\% CI: $17-33 \%)$, and NPV $(90 \%$; 95\% CI: $84-94 \%$ ) for report of wheezing were determined. Table 1 depicts the multivariate analysis on factors independently associated with disagreement between the firstly reported wheezing by the caregiver and the detection of wheezing by the pediatrician. Disagreement was higher when 
Table 1 Factors independently associated with disagreement between report of wheezing by the caregiver and detection of wheezing by the pediatrician

\begin{tabular}{|c|c|c|c|c|}
\hline \multirow[b]{2}{*}{ Characteristics* } & \multicolumn{2}{|c|}{$\begin{array}{l}\text { Discordance of report and detection of } \\
\text { wheezing }\end{array}$} & \multicolumn{2}{|l|}{ Analysis } \\
\hline & Yes $(n=110)$ & No $(n=171)$ & Unadj $\mathrm{PR}(95 \% \mathrm{Cl})$ & $\mathrm{Adj}_{\mathrm{dj}} \mathrm{PR}(95 \% \mathrm{Cl})$ \\
\hline \multicolumn{5}{|c|}{ Physical examination } \\
\hline Fever & $30 / 109(27.5) \dagger$ & $73 / 169(43.2) \dagger$ & $0.65(0.46-0.91)$ & $0.65(0.46-0.91)$ \\
\hline Tachypnea & $38 / 107(35.5) \dagger$ & $40 / 165(24.2) \dagger$ & $1.37(1.02-1.84)$ & $1.41(1.06-1.87)$ \\
\hline Red eyes & $19(17.3)$ & $50(29.2)$ & $0.64(0.42-0.97)$ & $0.66(0.44-0.99)$ \\
\hline Rhonchi & 48 (43.6) & 57 (33.3) & $1.30(0.97-1.73)$ & $1.40(1.06-1.86)$ \\
\hline
\end{tabular}

* Results in $\mathrm{n}(\%)$.

$\dagger$ †ifferent denominator due to missing data.

there was no other child aged under 10 years living in the same house $(43.7 \%$ vs. $30.6 \% ; \mathrm{p}=0.03)$.

Herein, wheezing on physical examination was detected in almost one-sixth $(16.4 \%)$ of the studied children. It was noteworthy the difference between the frequency of wheezing detected on physical examination $(16.4 \%)$ and the firstly reported wheezing by the caregiver (44.1\%). Interestingly, three quarters of children with report of wheezing did not present wheezing on physical examination; likewise, one-third of children with wheezing on physical examination were not reported to be wheezing. Wheezers may have not been recognized by parents or legal guardians because those children had never wheezed before. That is, there had not been the opportunity for families to learn how to recognize wheezing appropriately. On the other hand, report of wheezing may have been erroneous due to the recognition of other lower respiratory tract sound because rhonchi and tachypnea were directly associated with disagreement between report and detection of wheezing. Although possible, it is not probable that wheeze might have resolved when the child was examined because children were examined before any intervention in the hospital, and children with previous episodes of wheezing were excluded, excluding also the possible intervention at home, which can be given by experienced parents on wheezing. Conversely, the presence of fever and of red eyes on physical examination was inversely associated with such discordance (Table 1); that is, the presence of fever and red eyes helps on the agreement between the caregiver and the physician. Fever has been associated with wheezing because it is a general marker of infection (6), and lower respiratory tract infections have been associated with wheezing (7). Parents use multiple cues to identify wheezing and may even confound different respiratory sounds (8). In addition to that, patients with confirmed wheezing during the first year of life presented poorer lung function when they were compared with those whose parents had reported wheezing without confirmation (9). From our results, based on the high NPV, it is possible to highlight that the best performance for the caregiver report is when he/she denies wheezing (Table 1).

Methodological flaws must be recognized: As an observational study held in a pediatric hospital, the results may have been biased by parents' behavior in seeking for health assistance. The difficulty in capturing the concept of report of wheezing with a single definition has been emphasized (8). Different meanings may be influenced by factors such as the caregiver's educational background as well as the child and parent's respiratory history (8).

In conclusion, wheezing was firstly reported for almost half of children that present at the hospital with symptoms of a respiratory infection and that have not reported previous wheeze, among whom wheezing was firstly detected in onesixth. This is, the report of wheezing by the caregiver of a child who has never wheezed before requires confirmation by the pediatrician. If the child had not wheezed previously and the caregiver denies wheezing, it is highly probable that the child does not present it.

\section{Acknowledgments}

The authors are in debt to the pediatricians and nurses of the Professor Hosannah de Oliveira Pediatric Center, Federal University of Bahia, Salvador, Brazil, for their cooperation in recruiting the patients. Funding: This study was supported by Bahia State Agency for Research Funding (FAPESB). MariaRegina A. Cardoso, Dirceu Solé, Aldina Barral, and Cristiana M. Nascimento-Carvalho are investigators from the Brazilian Council for Scientific and Technological Development (CNPq). Maiara L. Bouzas was recipient of fellowship from $\mathrm{CNPq}$.

Maiara Lanna Bouzas ${ }^{1}$; Maria-Regina A. Cardoso ${ }^{2}$; Dirceu Solé ${ }^{3}$; Aldina Barral ${ }^{4}$; Cristiana

M. Nascimento-Carvalho ${ }^{1,5}$ \& The Acute Respiratory Infection and Wheezing Study Group Phase $\mathrm{I}^{5}$

${ }^{1}$ Postgraduate Program in Health Sciences, Federal University of Bahia School of Medicine, Salvador, Brazil; ${ }^{2}$ Department of Epidemiology, Faculty of Public Health, São Paulo University,

São Paulo, Brazil; ${ }^{3}$ Division of Allergy, Clinical Immunology and Rheumatology, Department of Pediatrics, Federal University of São Paulo, São Paulo, Brazil; ${ }^{4}$ Pathology Department, Federal University of Bahia School of Medicine, Centro de Pesquisa Gonçalo Muniz, Fundação Oswaldo Cruz, Salvador, Brazil; ${ }^{5}$ Department of Pediatrics, Federal University of Bahia School of Medicine, Salvador, Brazil.

E-mail: nascimentocarvalho@hotmail.com 


\section{References}

1. Linstow ML, Holst KK, Larsen K, Koch A, Andersen PK, Hogh B. Acute respiratory symptoms and general illness during the first year of life: a populationbased birth cohort study. Pediatr Pulmonol 2008: 43: 584-93.

2. Gern JE, Brooks GD, Meyer P, et al. Bidirectional interactions between viral respiratory illness and cytokine responses in the first year of life. J Allergy Clin Immunol 2006: 117: 72-8.

3. Tregoning JS, Schwarze J. Respiratory viral infections in infants: causes, clinical symptoms, virology, and immunology. Clin Microbiol Rev 2010: 23: 74-98.
4. El-Radhi AS, Barry W. Thermometry in paediatric practice. Arch Dis Child 2006: 91: 351-6.

5. World Health Organization., Integrated Management of Childhood Illness chart booklet. (WC 503.2). Geneva: WHO, 2008. Available at: http:// whqlibdoc.who.int/ publications/2008/9789241597289_eng.pdf. (accessed 15 January 2009).

6. Mommers M, Thijs C, Stelma F, et al. Timing of infection and development of wheeze, eczema, and atopic sensitization during the first $2 \mathrm{yr}$ of life: the KOALA Birth Cohort Study. Pediatr Allergy Immunol 2010: 21: 983-9.
7. Gern JE, Rosenthal LA, Sorkness RL, Lemanske RF Jr. Effects of viral respiratory infections on lung development and childhood asthma. J Allergy Clin Immunol 2005: 115: 668-74.

8. Fernandes RM, Robalo B, Calado C, et al. The multiple meanings of "wheezing": a questionnaire survey in portuguese for parents and health professionals. BMC Pediatrics 2011: 11: 112.

9. Lowe L, Murray CS, Martin L, et al. Reported versus confirmed wheeze and lung function in early life. Arch Dis Child 2004: 89 $540-3$.
Appendix 1. The Acute Respiratory Infection and Wheezing Study Group Phase I (in alphabetical order):

Eliana E. V. Silva ${ }^{1}$, Karen S. Miranda ${ }^{1}$, Laíse R. Néri ${ }^{1}$, Patrícia F. C. Silva ${ }^{1}$, Ramon S. Amoedo ${ }^{2}$, Rômulo B. Meneses ${ }^{1}$.
${ }^{1}$ Bahiana School of Medicine, Bahiana Foundation for Science Development, Salvador, Brazil.

${ }^{2}$ Federal University of Bahia School of Medicine, Salvador, 